\title{
Epileptogenesis
}

\author{
Asla Pitkänen ${ }^{1,2}$, Katarzyna Lukasiuk ${ }^{3}$, F. Edward Dudek ${ }^{4}$, and Kevin J. Staley ${ }^{5}$ \\ ${ }^{1}$ Department of Neurobiology, A. I. Virtanen Institute for Molecular Sciences, University of Eastern \\ Finland, Fl-70211 Kuopio, Finland \\ ${ }^{2}$ Department of Neurology, Kuopio University Hospital, FI-70211 Kuopio, Finland \\ ${ }^{3}$ The Nencki Institute of Experimental Biology, Polish Academy of Sciences, 02-093 Warsaw, Poland \\ ${ }^{4}$ Department of Neurosurgery, University of Utah School of Medicine, Salt Lake City, Utah 84108 \\ ${ }^{5}$ Department of Neurology, Massachusetts General Hospital, Boston, Massachusetts 02114 \\ Correspondence: asla.pitkanen@uef.fi
}

Epileptogenesis is a chronic process that can be triggered by genetic or acquired factors, and that can continue long after epilepsy diagnosis. In 2015, epileptogenesis is not a treatment indication, and there are no therapies available in clinic to treat individuals at risk of epileptogenesis. However, thanks to active research, a large number of animal models have become available for search of molecular mechanisms of epileptogenesis. The first glimpses of treatment targets and biomarkers that could be developed to become useful in clinic are in sight. However, the heterogeneity of the epilepsy condition, and the dynamics of molecular changes over the course of epileptogenesis remain as challenges to overcome.

In a mechanistic context, epileptogenesis is the process by which a brain network that was previously normal is functionally altered toward increased seizure susceptibility, thus having an enhanced probability to generate spontaneous recurrent seizures (SRSs) (Dudek and Staley 2012; Goldstein and Coulter 2013). Traditionally, epileptogenesis has been considered in the context of the "latent period," a pragmatic or operational term referring to the time period between the epileptogenic insult and the appearance of the first clinical seizure (Fig. 1). Many studies, however, have provided evidence that the frequency and severity of SRSs continue to increase after the first unprovoked or spontaneous seizure (Bertram and Cornett 1993, 1994; Hellier et al. 1998; Nissinen et al. 2000; Williams et al. 2009; Kadam et al. 2010), thus suggesting that epileptogenesis is a continuous and prolonged process. Furthermore, various forms of molecular and cellular plasticity, which are proposed to lead to the occurrence of the first unprovoked seizure, also continue indefinitely beyond the initial unprovoked seizure(s), and, thus, may contribute to the progression of the epileptic condition (for reviews, see Pitkänen et al. 2002; Rakhade and Jensen 2009; Dudek and Staley 2011, 2012; Pitkänen and Lukasiuk 2011). Many clinical studies have also independently suggested that human temporal lobe epilepsy, in particular, is progressive (Engel 1996, 2005, 2008; Berg and Engel 2006). Based on this data-derived conceptual evolution, the Working Group of the International League against

Editors: Gregory L. Holmes and Jeffrey L. Noebels

Additional Perspectives on Epilepsy: The Biology of a Spectrum Disorder available at www.perspectivesinmedicine.org

Copyright (C) 2015 Cold Spring Harbor Laboratory Press; all rights reserved; doi: 10.1101/cshperspect.a022822

Cite this article as Cold Spring Harb Perspect Med 2015;5:a022822 
A. Pitkänen et al.

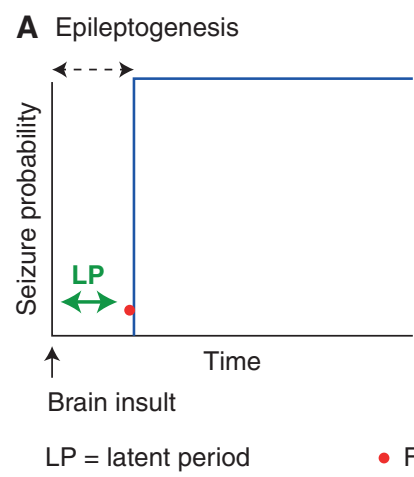

B Epileptogenesis

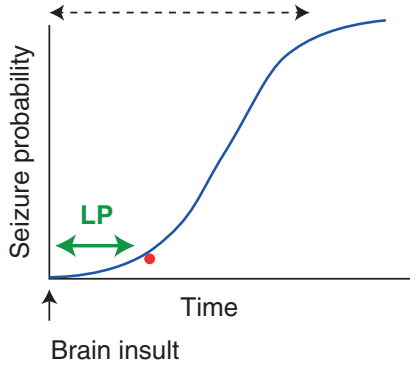

Figure 1. Definitions of epileptogenesis. (A) Previously, epileptogenesis was considered to be represented by the latent period, which has been defined as the time between the precipitating insult and the occurrence of the first unprovoked clinical seizure. Thus, the temporal development of acquired epilepsy was previously considered to be a step function of time. $(B)$ More recently, based on several experimental and clinical observations, epileptogenesis is now considered to extend beyond the latent period, which is still defined as the time from the precipitating injury and the first clinical seizure. However, the observations that subconvulsive seizures may well have occurred before the first clinical seizure and that seizure frequency and severity progressively increase over time both indicate the epileptogenesis can continue indefinitely (based on data from Williams et al. 2009 and Kadam et al. 2010).

Epilepsy (ILAE) revised the terminologies related to disease modification, including epileptogenesis. These conceptual changes have important implications to how experimental epilepsy researchers create and analyze animal models of acquired epilepsy, how hypothetical treatments are developed and tested, and how biomarkers may be identified and implemented (Pitkänen et al. 2013; Pitkänen and Engel 2014).

According to the new terminology, epileptogenesis refers to the development and extension of tissue capable of generating SRSs, resulting in (1) development of an epileptic condition, and/or (2) progression of the epilepsy after it is established. The major difference to the previous concept is that the term "epileptogenesis" no longer refers only to the time period between the epileptogenic insult and diagnosis of epilepsy (Fig. 1A); rather, the term epileptogenesis now includes the mechanisms of progression that can continue to occur even after the diagnosis of epilepsy (Fig. 1B). Epileptogenesis is often associated with comorbidities, which may originate from overlapping networks (Kanner et al. 2014) and/or result from the effects of SRSs. Thus, disease or syndrome modification has two components: antiepileptogen- esis (AEG) and comorbidity modification. AEG is considered to be a process that counteracts the effects of epileptogenesis, including prevention, seizure modification, and cure. Prevention can be complete or partial. Complete prevention aborts the development of epilepsy. Partial prevention can delay the development of epilepsy or reduce its severity. For example, in this scenario, seizures occur but they may be fewer in frequency, shorter in duration, or of milder seizure type (seizure modification). AEG could also prevent or reduce the progression of epilepsy after it has already been established. Cure refers to a complete and permanent reversal of epilepsy, such that no seizures occur after treatment withdrawal. Antiepileptogenic treatment can be given before or after epilepsy onset. When an antiepileptogenic treatment is given before epilepsy onset, it prevents or delays the development of epilepsy. This is to be distinguished from insult modification, however, in which a treatment is administered before the onset of epilepsy and alters epileptogenesis by modifying the insult itself. If SRSs occur in either case, the seizures may be fewer, shorter, milder, or more sensitive to pharmacotherapy; in addition, progression may be reduced. When such 
a treatment is given after the diagnosis of epilepsy, it can alleviate the same properties of the seizures/epilepsy, but then the effect is clearly antiepileptogenic and not insult modifying. Comorbidity-modifying treatment alleviates or reverses the symptomatic development or progression of epilepsy-related comorbidities, such as anxiety, depression, somatomotor impairment, or cognitive decline (Pitkänen et al. 2013; Pitkänen and Engel 2014). Both antiepileptogenic and comorbidity-modifying treatments can also alleviate or reverse the associated pathology.

We will next give examples of epileptogenesis in humans, focusing on epileptogenesis after stroke, traumatic brain injury (TBI), and status epilepticus (SE), which can also be modeled in rodents. Then, we will briefly summarize the recent developments in our understanding of the molecular aspects of epileptogenesis, current status in the development of AEG treatments, and identification of biomarkers for epileptogenesis.

\section{HUMAN STUDIES}

The rate of epileptogenesis after acquired brain insults in humans has been most extensively studied after stroke, TBI, and SE (Fig. 2). Possibly related to the incidence of the epileptogenic etiology, there are many more studies on epileptogenesis after stroke or TBI than after SE in humans. Based on these data, the incidence of acquired epilepsy is highest in the first years postinjury. A decade after injury, the incidence of epilepsy, even though still present, is significantly lower (e.g., Annegers et al. 1998). Interestingly, the rate of epileptogenesis differs between the brain insults, being the highest after acute symptomatic seizure (structural, metabolic, anoxic encephalopathy) associated with $\mathrm{SE}>$ acute symptomatic seizure $\approx$ stroke (on average $) \approx$ severe TBI $>$ moderate TBI (Fig. 2$)$ (Annegers et al. 1998; Hesdorffer et al. 1998; Graham et al. 2013). Importantly, the risk of epilepsy varies not only between the diagnostic categories of stroke, TBI and SE, but also within these diagnoses. This is a consequence of the wide variety of pathologies included under each term, including, for example, hemorrhagic versus ischemic stroke or subdural hemorrhage versus cortical contusion for TBI (Annegers et al. 1998; Hesdorffer et al. 1998; Saatman et al. 2008; Arntz et al. 2013; Graham et al. 2013). Moreover, evidence is accumulating that acquired epileptogenesis is modulated by

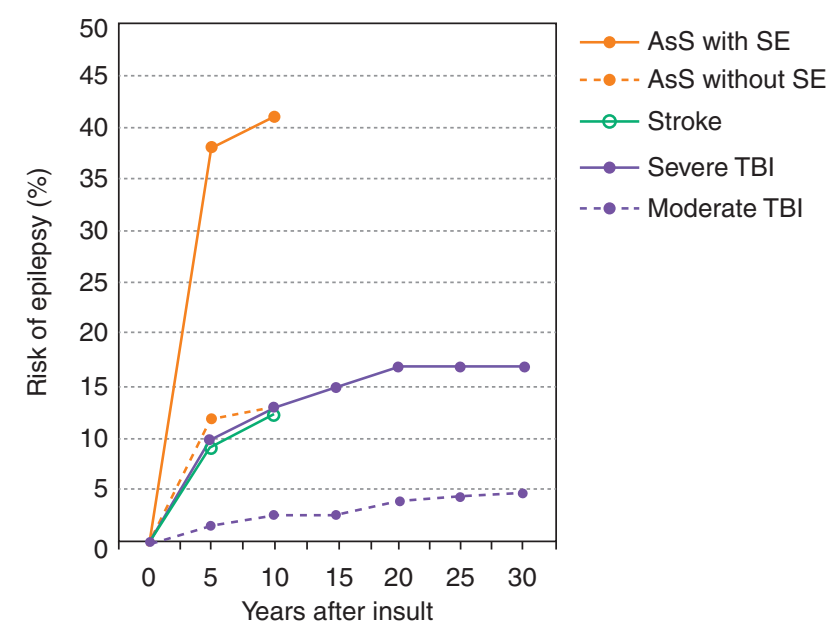

Figure 2. Development of epilepsy after status epilepticus (SE) (Hesdorffer et al. 1998), stroke (Graham et al. 2013), and traumatic brain injury (TBI) (Annegers et al. 1998) in humans. Note the similarity in the rate of epileptogenesis after severe TBI, stroke (average of different types of stroke) (Graham et al. 2013), and acute symptomatic seizure (AsS) without SE. 
A. Pitkänen et al.

genetic and environmental influences in a given individual (Miller et al. 2010; Wagner et al. 2010; Darrah et al. 2013; Ndode-Ekane and Pitkänen 2013; Diamond et al. 2014; Henshall et al. 2014; Kobow and Blümcke 2014). All of these aspects pose challenges for the analysis or prediction of epileptogenesis in human populations. However, the emerging details of human epileptogenesis also provide information for optimizing the animal modeling of etiologyspecific epileptogenesis in search of novel AEG biomarkers and therapies (Engel et al. 2013; Pitkänen et al. 2013).

\section{EXPERIMENTAL STUDIES－ADULTS}

In Vivo Models of Epileptogenesis

\section{Models of Epilepsy Based on Status Epilepticus}

The experimental studies on animal models of acquired epilepsy have been dominated by research using various forms of SE. This line of research was based on numerous publications showing that injections of chemoconvulsants, such as kainic acid and pilocarpine, or repetitive electrical stimulation of structures, such as the hippocampus or amygdala, can lead to a chronic epileptic state with robust convulsive SRSs. Numerous variations of these models have been developed, such as intrahippocampal or intra-amygdala kainate or repeated low-dose systemic kainate (Hellier et al. 1998). Given the limited space here, our focus will be on a few studies that have used long-term, continuous, video-EEG to determine the life history of this form of acquired epileptogenesis. Bertram and Cornett $(1993,1994)$ performed prolonged video EEG and showed that the frequency of SRSs generally increased with time after the SE, but appeared to level off eventually. As expected, the SRSs did not occur for a week or two after the SE ("latent period"), and the initial seizures were primarily nonconvulsive but subsequent seizures were convulsive, typically lasting tens of seconds and each having a progressive evolution, often with postictal depression. The seizures often occurred in clusters (Goffin et al. 2007; Williams et al. 2009). Similar data were obtained with an animal model of TLE based on electrical stimulation of the amygdala (Nissinen et al. 2000). Williams et al (2009), using a repeated low-dose systemic kainate model (Buckmaster and Dudek 1997; Hellier et al. 1998), confirmed and extended these data and emphasized the sigmoidal nature of the life history of the progressive epilepsy. They also proposed that the latent period was a time of increasing seizure probability, and was theoretically equivalent to the time point when seizure probability asymptotically departs substantially from a normal baseline of low-seizure probability; therefore, the concept that acquired epileptogenesis is a continuous process best described by a sigmoid function of time implies that the latent period is a poor measure of epileptogenesis in both experimental and clinical studies. Considering acquired epileptogenesis as a continuous process begs the question of how are the operative mechanisms similar or different before versus after the first unprovoked seizure.

\section{Models of Poststroke Epilepsy}

Table 1 summarizes the experimental studies on poststroke epilepsy in adult animals. Studies have focused on modeling of focal stroke caused by thrombus/embolus or vasospasm. None of the studies has taken into account comorbidities (e.g., hypertension or hyperlipidemia), which are often associated with stroke in humans, and only a few endophenotypes of stroke have been investigated (Casals et al. 2011). Also, the age of animals at the time of stroke has typically been young adulthood, but stroke is most prominent in the elderly and also common in the perinatal period. Follow-up times of animals have been variable but often prolonged, in some cases for up to 20 months poststroke. The percentage of animals shown to develop epilepsy, as well as the seizure frequency during the monitoring period(s) have been variable, and it is unclear whether the variability is model dependent or is because differences in the severity of the injury or to other experimental factors. A key issue in studies of poststroke epilepsy has been the distinction of what is a seiz- 
Epileptogenesis

Table 1. Epileptogenesis after experimental stroke

\begin{tabular}{|c|c|c|c|c|c|c|}
\hline $\begin{array}{l}\text { Method of } \\
\text { induction }\end{array}$ & Lesion & $\begin{array}{c}\text { Follow- } \\
\text { up }\end{array}$ & $\begin{array}{c}\text { Epilepsy } \\
(\%)\end{array}$ & Sz frequency & Sz duration & References \\
\hline \multirow{5}{*}{$\begin{array}{l}\text { Cortical } \\
\text { photothrombosis }\end{array}$} & Motor Cx & $4 \mathrm{mo}$ & $50 \%$ & Multiple & $90 \mathrm{sec}$ & Kelly et al. 2001 \\
\hline & S1 & $8 \mathrm{mo}$ & $75 \%$ & Frequent & $\sim 13 \mathrm{sec}$ & Kelly et al. 2001 \\
\hline & S1 & $4 \mathrm{mo}$ & $100 \%$ & Daily recurrent & $\sim 10 \mathrm{sec}$ & Liu et al. 2002 \\
\hline & S1 & $6 \mathrm{mo}$ & $50 \%$ & $1 / 4.6 \mathrm{~h}$ & $2-3 \mathrm{sec}$ & Kharlamov et al. 2003 \\
\hline & S1 & $10 \mathrm{mo}$ & $19 \%$ & $0.39 \mathrm{Sz} / \mathrm{d}$ & $117 \mathrm{sec}$ & Karhunen et al. 2007 \\
\hline Transient MCAO & & $12 \mathrm{mo}$ & $0 \%$ & - & - & Karhunen et al. 2003 \\
\hline Permanent MCAO & & $20 \mathrm{mo}$ & $100 \%$ & $4 /$ wk & $6 \mathrm{sec}$ to $1 \mathrm{~min}$ & Kelly et al. 2006 \\
\hline Endothelin-1 & $\begin{array}{c}\mathrm{Cx} \\
\text { Striatum }\end{array}$ & $12 \mathrm{mo}$ & $3 \%$ & $0.21 / \mathrm{d}$ & $78-174 \mathrm{sec}$ & Karhunen et al. 2006 \\
\hline Endothelin-1 & $\mathrm{HC}$ & $3 \mathrm{mo}$ & $92 \%$ & $1.8 / \mathrm{d}$ & $6-7 \mathrm{sec}$ & Mátéffyová et al. 2006 \\
\hline
\end{tabular}

ure characteristic of acquired epilepsy, versus a spike-wave discharge commonly seen in some rodent strains (Kelly 2004; Kelly et al. 2006; Pearce et al. 2014).

\section{Models of Posttraumatic Epilepsy (PST)}

Table 2 summarizes the studies that have reported the occurrence of spontaneous seizures after experimental TBI. Like after stroke, only a few endophenotypes in humans or models of TBI have been investigated (Saatman et al. 2008; Xiong et al. 2013). The issue raised above concerning what is a seizure characteristic of acquired epilepsy versus a normal spike-wave discharge seen in controls is a concern with regard to PTE (D'Ambrosio et al. 2009; D'Ambrosio and Miller 2010; Dudek and Bertram 2010). The data available appear to show that both focal contusion as well as TBI associated with both gray and white matter damage can result in epileptogenesis (Table 2), but more work is required with an emphasis on also recording from age-matched controls. In most cases, as with stroke, epileptogenesis appears to be slow and occurs only in a subset of animals, and seizure frequency is low.

\section{In Vitro Models of Epileptogenesis}

The sections described above highlight the technical and practical difficulties in studying epileptogenesis in intact, freely behaving animals, which are necessary to link epileptiform activity to the behavioral features of seizures that form the basis of acquired epilepsy. In vitro models of epileptogenesis are useful by virtue of the experimental accessibility of these systems and the rapid time course of the development of electrographic features of epilepsy (McBain et al. 1989; Bausch and McNamara 2000). Importantly, the organotypic hippocampal slice culture can be maintained stably for weeks in vitro, which make them applicable for epileptogenesis studies. Under standard culture conditions and in the absence of additional convulsant manipulations, spontaneous electrographic activity that closely resembles interictal spikes develops in the first week in vitro, and seizure-like epileptiform activity develops during the second week in vitro (DyhrfjeldJohnsen et al. 2010; Berdichevsky et al. 2012, 2013). The seizure-like, but not spike-like activities, are suppressed by standard anticonvulsants, such as phenytoin, corresponding to the effects of these drugs in human epilepsy patients (Berdichevsky et al. 2012). More rapid development of electrographic features of epilepsy can be obtained in vitro by exposing the acute hippocampal preparation to additional convulsant conditions, such as repeated electrical stimulation, removal of magnesium from the perfusate, or exposure to kainic acid, but the clinical relevance of these additional manipulations are 
A. Pitkänen et al.
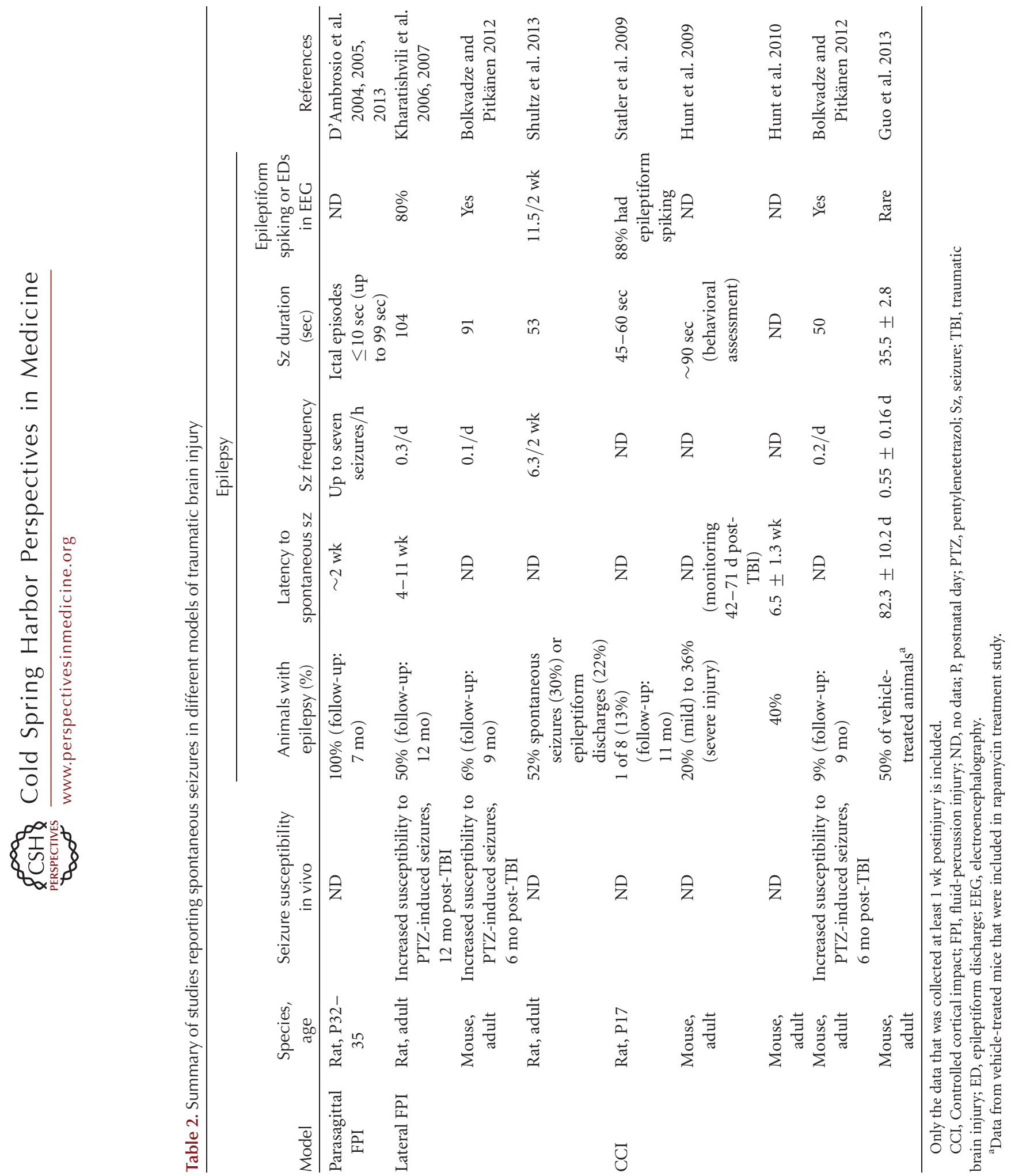
difficult to discern ( reviewed in Heinemann and Staley 2014).

\section{CELLULAR AND NETWORK MECHANISMS OF EPILEPTOGENESIS}

Most of the information that our understanding of epileptogenesis relies on comes from studies on SE and focus on hippocampus. Computational models of epilepsy based on that information have robustly converged on the concept that excitatory positive feedback is a necessary characteristic of epileptic networks (Soltesz and Staley 2008). One feature of such networks is bistability, that is, the capacity to switch back and forth between normal and epileptic modes of activity (Jirsa et al. 2014). To understand epileptogenesis, we might ask what underlies the development of this positive feedback? Two answers have been proposed. One possibility is that preexisting positive feedback is uncovered because of the loss of inhibitory circuitry ( $\mathrm{Du}$ dek and Staley 2012), for example, the loss of hilar mossy cells that excite inhibitory basket cell interneurons in the dentate gyrus (Sloviter 1991). Normal neural networks have moderate amounts of positive feedback as a consequence of recurrent glutamatergic connectivity between principal neurons. In the acute hippocampal slice preparation, the fraction of neuron pairs with monosynaptic excitatory interconnections has been estimated to be $\sim 1 \%-3 \%$ (e.g., MacVicar and Dudek 1980; Miles and Wong 1987). This number is likely to be a significant underestimate of the in vivo connectivity owing to the degree of deafferentation caused by slicing. However, data regarding the degree and anatomical patterns of neuronal interconnectivity are exceptionally sparse because of the technical difficulty of establishing synaptic connectivity between neurons, and establishing this "connectome" is a central goal of the National Institutes of Health BRAIN project (Kandel et al. 2013). Unmasking this normal positive feedback caused by damage to inhibitory neurons and their circuitry (Shao and Dudek 2005) could provide a means to increase the net functional positive feedback in epilepsy (Cronin et al. 1992). Ultrastructural analyses of the dentate gyrus during epileptogenesis revealed more $\gamma$-aminobutyric acid (GABAergic) terminals after the time of onset of spontaneous seizures, suggesting that some aspects of GABAergic synaptic transmission may not be functional (Thind et al. 2010).

A second mechanism for the development of positive feedback is the sprouting of new synaptic connections between surviving, deafferented neurons after brain injury (Tauck and Nadler 1985; Cronin et al. 1992; Wuarin et al. 1996; Sutula and Dudek 2007; Buckmaster 2012). Axon sprouting is a well-established reparative response to a variety of brain injuries (Schauwecker et al. 2000), and we do not know for certain whether sprouting is necessary for epilepsy (Lew and Buckmaster 2011). Although the molecular signaling regulating sprouting is being actively investigated in the spinal cord (Giger et al. 2010), we do not know what principles guide the sprouting; for example, if GABAergic axon sprouting or glutamatergic sprouting onto interneurons predominates (Babb et al. 1989; Zhang et al. 2009), sprouting of GABAergic terminals could be a powerful antiepileptogenic mechanism. We are just beginning to discover the strategies that neurons use to connect to other neurons (Bonefazzi et al. 2011; Perin et al. 2011), and we have essentially no data regarding the strategies used to restore neural connections after injury. Axon sprouting thus has a strong correlation with epileptogenesis (e.g., Gorter et al. 2001), but much work needs to be performed to elucidate the details of the circuit alterations engendered by sprouting, and the mechanisms by which these alterations engender seizures.

\section{MOLECULAR MECHANISMS OF EPILEPTOGENESIS}

The introduction of methods that allow global analyses of transcriptome, epigenome, proteome, or metabolome have raised expectations for pinpointing the molecular mechanisms of epileptogenesis, which would lead to identification of novel targets for AEG therapies. However, most "omics" studies describe acute molecular pathologies occurring within a few days 
A. Pitkänen et al.

after an epileptogenic insult, and, therefore, it has been difficult to interpret whether they represent injury effects rather than mechanisms leading to epileptogenesis. Most of the human data available come from samples collected from surgically operated patients, thus presenting the end stage of the disease. Relatively few studies have specifically addressed epileptogenesis, which might optimally be performed by studying the tissue near the end of the latent period or early after the appearance of SRSs (Table 3).

The majority of "omics" studies in epileptogenesis concern evaluation of alterations in gene expression, which is because of the availability of affordable microarrays as well as sequencing technologies. Changes in expression of hundreds of genes have been reported in animal models. Interestingly, very few of these genes have been found to have abnormal regulation in more than one study or model (Lukasiuk et al. 2006; Pitkänen and Lukasiuk 2011). Moreover, studies in which tissue sampling was performed over time after an epileptogenic insult indicate that individual genes show different temporal expression profiles. At the same time, it is possible to identify ensembles of genes that change their expression levels in a coordinated way (Lukasiuk et al. 2006; Pitkänen and Lukasiuk 2011). These data suggest that changes in the transcriptome during the course of epileptogenesis are time specific and dynamic, although there are no studies that had been designed to answer this question specifically. However, the data already available have significant implications for AEG therapy development strategies. For example, it is likely that one has to tailor the therapy approach depending on the timing relative to the occurrence of epileptogenic brain insult and its type.

In-depth analyses of large-scale data sets allows identification of molecular and functional gene and/or protein networks affected by an epileptogenic insult itself, or by later epileptogenesis, and have resulted in formulation of testable hypotheses about the molecular changes that could be relevant for epileptogenesis. These include involvement of proteolytic cascades (Gorter et al. 2007), transforming growth factor $\beta$ (TGF- $\beta$ ) and insulin-like growth fac- tor 1 (IGF-1) signaling (Cacheaux et al. 2009), p38MAPK, Jak-STAT, PI3K, mammalian target of rapamycin (mTOR) (Okamoto et al. 2010), complement activation (Aronica et al. 2007), and gene expression modulation related to glial oxidative stress and synaptic vesicle trafficking in epileptogenesis (Winden et al. 2011). An obvious question related to changes in the transcriptome is: What controls gene expression? If there is a master switch, could it be targeted to normalize the gene-expression patterns? Interesting candidates are transcription factors, which can control expression of many genes. For example, inducible cAMP early repressor (ICER) has been suggested to play a role in epileptogenesis as it suppresses kindling (Kojima et al. 2008; Porter et al. 2008). Other candidates include cAMP response element (CREB), controlling differential expression of genes in human epileptic cortex (Beaumont et al. 2012), and repressor element-1 silencing transcription factor (NRSF) shown to repress epileptogenesis in a kindling model and reported to regulate target genes relevant for neuronal network remodeling in kainate-induced SE (Hu et al. 2011; McClelland et al. 2014).

Another level of regulation of gene expression is epigenetic regulation, which can present as an alteration in DNA methylation or histone modifications, or by transcriptional regulation by micro-RNAs (miRNAs). Although there are studies showing altered DNA methylation of individual genes during the latent period as well as during the chronic phase, large-scale profiling data are not available on epigenome modifications in epileptogenesis (Pitkänen and Lukasiuk 2011; Kobow et al. 2013; Kobow and Blümcke 2014). The only data on global changes in DNA methylation in epilepsy come from the work of Kobow et al. (2013), who found alterations in DNA methylation patterns in chronically epileptic rats in the pilocarpine model of TLE. There are, however, few "omics" datasets describing alterations in miRNA expression during epileptogenesis (Table 3), indicating that, similar to mRNA, changes in miRNA expression are dynamic and time dependent. Also, as in the case of mRNA profiling, differentially expressed miRNAs differ from study to study, which can 
Epileptogenesis
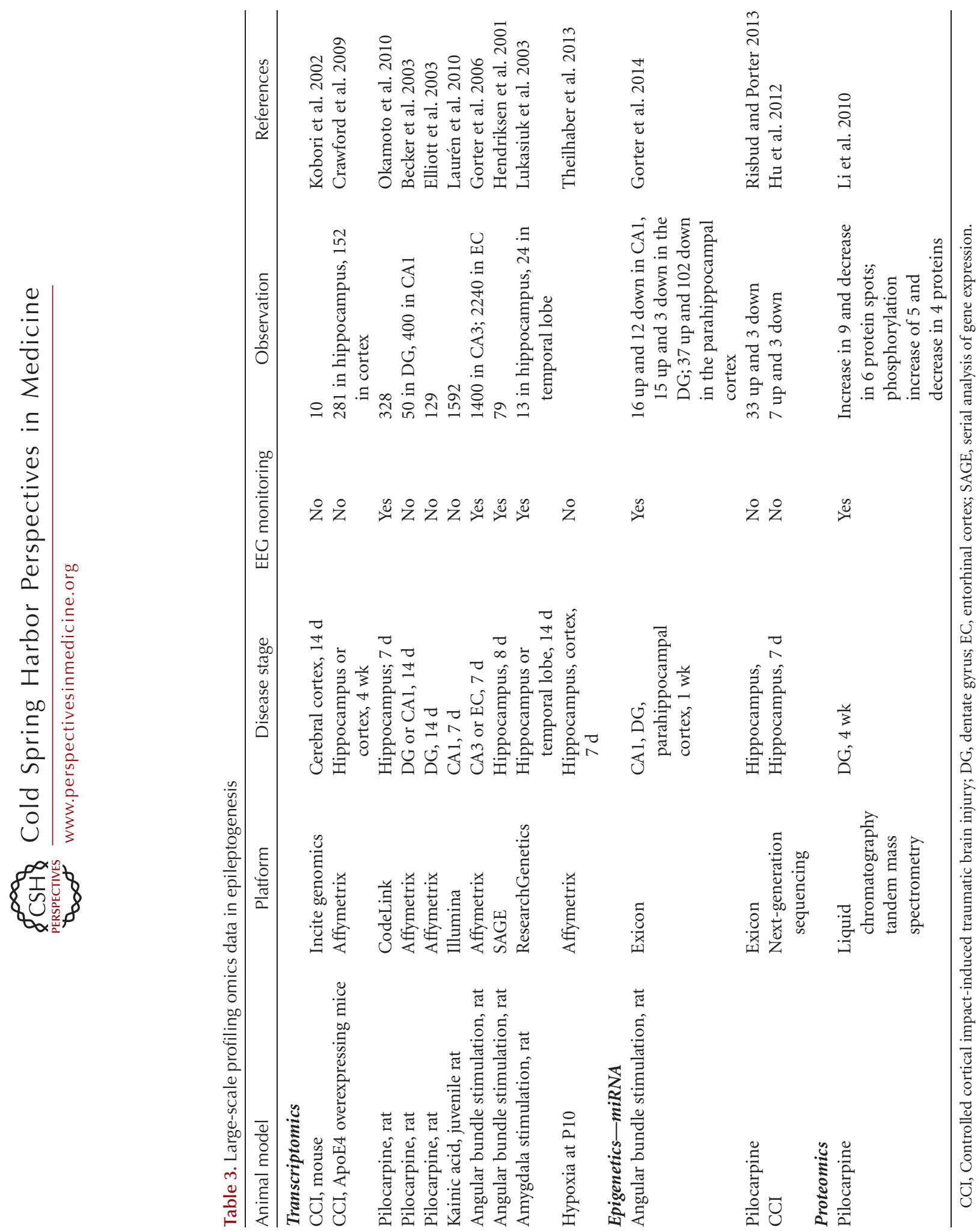
A. Pitkänen et al.

be explained by different timing of tissue sampling, animal model used, or the brain area profiled. Interestingly, however, some common features can be found. For example, alterations in miR-21, miR-34a, miR-132, or miR-146a are commonly found in animal models of epileptogenesis. Functions of some of these miRNAs can be linked to epileptogenesis. For example, miR-146a, which is critical for regulation of astrocyte-mediated inflammatory response, is up-regulated in activated astrocytes during epileptogenesis (Aronica et al. 2010; Iyer et al. 2012; Jovičić et al. 2013). miR-132, a miRNA that influences neuronal morphology by increasing dendritic outgrowth and arborization, and participating in regulation of spine density, is enriched in neurons and consistently up-regulated following epileptogenic stimuli (Jovičić et al. 2013). Recently, Bot et al. (2013) made an attempt to predict the functional impact of changes in miRNA expression during epileptogenesis by analyzing the expression of their potential mRNA targets. The data revealed that the protein products of miRNA-regulated mRNAs were involved in different types of molecular processes, including the regulation of transcription, second messenger signaling, ion homeostasis, immune response, response to wounding, and regulation of cell death (Bot et al. 2013). The significance of these complex changes in the expression of miRNAs during epileptogenesis is still difficult to interpret, and will require gathering more information on the function miRNA expression in the brain tissue and in-depth knowledge on the targets of each miRNA.

Large-scale proteomics studies are rare. $\mathrm{Li}$ et al. (2010) analyzed the proteome of the dentate gyrus after pilocarpine-induced SE using two-dimensional gel electrophoresis, followed by liquid chromatography, and tandem mass spectrometry. They found 24 differentially expressed proteins, including nine phosphoproteins. Interestingly, some of the regulated proteins were involved in synaptic physiology ( $\mathrm{Li}$ et al. 2010).

In the long term, identification of the molecular pathways that lead to epileptogenesis after brain injury is a critical goal that could in theory lead directly to AEG therapies. This overall approach, however, has long been plagued by a lack of reproducibility, likely stemming from methodological variability and statistical problems related to small sample size and multiple comparisons (Ioannidis et al. 2009). Moreover, the newly identified pathways could simply reflect brain injury versus epileptogenesis versus recovery processes. Overall, these molecular approaches have yet to provide substantive insight into acquired epileptogenesis, and further studies that directly compare different animal models with careful consideration of the timeline of molecular events in relation to seizure frequency/probability (i.e., epileptogenesis) may provide important information in the future.

\section{BIOMARKERS OF EPILEPTOGENESIS}

\section{Definitions}

The ILAE Working Group for epilepsy biomarkers recently published a taskforce report (Engel et al. 2013). A biomarker is defined as an objectively measured characteristic of a normal or pathologic biologic process, such as blood sugar in diabetes and prostate-specific antigen in prostate cancer. Biomarkers of epileptogenesis could (1) predict the development of an epilepsy condition, (2) identify the presence and severity of tissue capable of generating spontaneous seizures, (3) measure progression after the condition is established, (4) be used to create animal models for more cost-effective screening of potential antiepileptogenic drugs and devices, and (5) reduce the cost of clinical trials of potential antiepileptogenic interventions by enriching the trial population with patients at high risk for developing epilepsy.

\section{Molecular Biomarkers}

The availability of molecular biomarkers, especially those easily accessible from body fluids would be of particular importance in identifying patients who will eventually develop epilepsy after brain insult. Discovery of molecular biomarkers of epileptogenesis is significantly impeded by the dynamic nature of this process. Both imaging and molecular data indicate that 
pathological changes associated with epileptogenesis (gliosis, blood-brain barrier dysfunction, neurodegeneration, aberrant plasticity, neurogenesis, and channelopathies) develop in time, can occur sequentially and in parallel, and possibly depend on etiology (Pitkänen and Lukasiuk 2011; Lukasiuk and Becker 2014). Therefore, different sets of biomarkers may be necessary for different stages and etiologies of epileptogenesis. Another challenge is to identify biomarkers that will be sensitive and specific for epileptogenesis, rather than the severity of brain injury. Moreover, the predictive value of biomarkers should not be compromised by concomitant peripheral injury-related complications.

The ideal biomarker for epileptogenesis should be sensitive, specific, and feasible (i.e., easily accessible). The candidate platforms would include noninvasive brain imaging or electrophysiological recordings, or be derived from peripheral tissues. Currently, such validated biomarkers have not been identified. Although there are some candidates proposed based on studies, reporting a correlation between the biomarker level and seizure frequency, the sensitivity and specificity of candidate biomarkers have not been assessed. These approaches include evaluation of brain metabolites using brain imaging of glucose metabolism (Filibian et al. 2012; Guo et al. 2013; Shultz et al. 2013), plasma inflammatory proteins (C reactive protein $[\mathrm{CRP}]$ ), interleukin (IL)-1 $\beta$ and IL6) (Holtman et al. 2013), and plasma markers of brain injury in TBI models (e.g., S100B, neuron specific enolase [NSE], glial fibrillary acidic protein [GFAP], ubiquitin carboxyl-terminal hydrolase L1 [UCHL1], myelin basic protein $[\mathrm{MBP}$ ], and tau) (see Lukasiuk and Becker 2014). Recently, serum and plasma miRNAs have been proposed as biomarkers for epileptogenesis after SE or TBI, but the validation studies remain to be performed (Liu et al. 2010; Zhang et al. 2011; Gorter et al. 2014).

\section{Electrographic Biomarkers}

After an unprovoked seizure, patients are typically evaluated with an EEG recording. The presence of electrographic interictal spikes in such a recording supports a diagnosis of epilepsy, but does not address a critical question: What comes first, the spikes or the seizures? If the spikes develop before seizures, they could represent an important biomarker of epileptogenesis. Early epileptiform activity in electrographic recordings is a promising predictor of epilepsy after brain injury induced by kainic acid (White et al. 2010). Similar results were obtained in vitro in the organotypic hippocampal slice culture model of epileptogenesis (Dyhrfjeld-Johnsen et al. 2010). These studies undertook a simple but important step beyond prior EEG biomarker studies by greatly increasing the duration of the EEG sample from the standard clinical EEG of tens of minutes up to 24-h recording epochs (Jennett and Van De Sande 1975). Although the results in these experimental studies are promising and support the possibility that EEG biomarkers may be useful for the prediction of acquired epilepsy, the predictive power of electrographic biomarkers has not been systematically compared with the predictive power of traditional physical descriptors of injury, such as lesion size and location. Furthermore, it has not been determined whether combining electrographic and physical-injury parameters would improve their predictive power. Finally, the optimal timing of the EEG sample relative to injury has not been determined. These issues must be addressed experimentally in prospective studies of epileptogenesis after stroke and TBI.

\section{Imaging Biomarkers}

Among the different investigational platforms, magnetic resonance imaging (MRI) provides an appealing approach to follow epileptogenesis over time to identify biomarkers for epileptogenesis with high sensitivity and specificity. Two recent publications have strengthened this view. Immonen et al. (2013) reported that diffusion trace (Dav), T1rho, and T2 alone or in combination when assessed within the first 2 mo postinjury predicted the seizure susceptibility at 12 mo post-TBI. Choy et al. (2014) reported that amygdala T2 values $2 \mathrm{~h}$ after experimental 
A. Pitkänen et al.

febrile SE distinguished rats that progressed on to epilepsy or not. Even though further studies are needed to confirm these findings in larger cohorts of animals, these data suggest that epileptogenesis triggered by different brain insults can be biomarked.

\section{ANTIEPILEPTOGENESIS}

\section{Proof-of-Concept Studies in In Vivo Models}

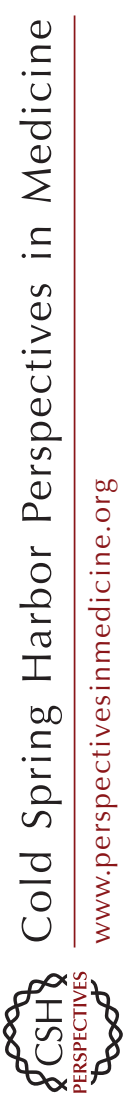

Antiepileptic drugs (AEDs), such as phenytoin, phenobarbital, carbamazepine, or valproic acid, were used in the first attempts to prevent epileptogenesis in humans (for review, see Temkin 2001). More recent clinical trials, in which the development of epilepsy was the primary or secondary outcome measure investigated molecules with neuroprotective properties, in addition to newer AEDs (Pitkänen and Immonen 2014; Trinka and Brigo 2014). The first proofof-concept experimental AEG studies $\sim 15$ years ago were also performed using standard AEDs, and treatments targeting the molecular and cellular mechanisms related to circuitry reorganization were introduced more recently (see Pitkänen and Kubova 2004; Pitkänen and Lukasiuk 2011). Still, in 2014, there are no clinically available AEGs, and epileptogenesis is not considered a treatment indication. Preclinical proof-of-concept studies, however, have provided promising evidence that epileptogenesis triggered by genetic or acquired insults can be modified. In fact, 47 experimental treatments have been studied, most of which have shown some favorable disease-modifying effect in experimental proof-of-concept studies (Table 4) (for details, see Table 1 in Pitkänen et al. 2014). However, none of these have progressed to clinic. Also, none of the treatments being tested in clinic were vigorously assessed in preclinical models (Trinka and Brigo 2014).

A difficulty with antiepileptogenic trials is the time involved in epileptogenesis, and the effort involved in quantification of seizure frequency at a resolution that enables the evaluation of candidate therapies. One approach to these problems is to use in vitro preparations of epileptogenesis (Simonato et al. 2012). The organotypic slice preparation has been pro-

Table 4. Summary of treatments showing antiepileptogenic effects or reduction in seizure susceptibility

\begin{tabular}{|c|c|c|c|c|}
\hline SE & TBI & Hyperthermia & $\begin{array}{c}\text { Cortical } \\
\text { malformation }\end{array}$ & Genetic \\
\hline Atipamezole & $\begin{array}{l}\text { SR141716A } \\
\text { (Rimonabant) }\end{array}$ & $\begin{array}{l}\text { SR141716A } \\
\text { (Rimonabant) }\end{array}$ & Rapamycin & Levetiracetam \\
\hline Celecoxib & $\begin{array}{l}\text { Minozac } \\
\text { Ceftriaxone }\end{array}$ & & & $\begin{array}{l}\text { Ethosuximide } \\
\text { Zonisamide }\end{array}$ \\
\hline$\alpha_{4}$ Integrin specific mAb & Rapamycin & & & Vigabatrin \\
\hline Erythropoietin & & & & Rapamycin \\
\hline FGF-2 and BDNF gene therapy & & & & \\
\hline Rapamycin & & & & \\
\hline Parecoxib & & & & \\
\hline $\begin{array}{l}\text { NRSE-sequence decoy } \\
\text { oligodeoxynucleotides }\end{array}$ & & & & \\
\hline Aspirin & & & & \\
\hline Fingolimod (FTY720) & & & & \\
\hline Pentylenetetrazol & & & & \\
\hline Adenosine & & & & \\
\hline Melatonin & & & & \\
\hline 1NMPP1 & & & & \\
\hline WP1066 & & & & \\
\hline
\end{tabular}

For details, see Pitkänen et al. (2014).

SE, Status epilepticus; TBI, traumatic brain injury; FGF, fibroblast growth factor; BDNF, brain-derived neurotrophic factor. 
posed as one model for screening of antiepileptogenic therapies, and initial studies with mTOR antagonists have supported the utility of this preparation in rapidly dissecting complex signaling pathways (Berdichevsky et al. 2013). However, it will be important to subject the findings obtained in vitro to subsequent in vivo replication studies, particularly in cases in which complex in vivo results have been obtained (Lew and Buckmaster 2011; Guo et al. 2013).

\section{CONCLUDING REMARKS}

Epileptogenesis and its treatment are research priorities on the political agendas both in Europe and the United States (Baulac and Pitkänen 2009; Kelley et al. 2009). The modeling of epileptogenesis and understanding of the molecular mechanisms of epileptogenesis are progressing fast. Efforts need to be put on using all available tools and information for identification of treatment targets and biomarkers, which will fasten the translation of laboratory discoveries to clinic.

\section{ACKNOWLEDGMENTS}

This work is supported by the Academy of Finland (A.P.), UEF Spearhead Project "UEF-Brain" (A.P.), ERA-NET NEURON II FA0200006175 (A.P.), Polish National Research Centre Grant 2011/01/M/NZ3/02139 (K.L.), Polish Ministry of Science and Education Grant DNP/N119/ESF-EuroEPINOMICS/ 2012 (K.L.), and the United States National Institutes of Health Grant R01NS086364 (F.E.D. and K.J.S.).

\section{REFERENCES}

Annegers JF, Hauser WA, Coan SP, Rocca WA. A populationbased study of seizures after traumatic brain injuries. 1998. N Engl J Med 338: 20-24.

Arntz R, Rutten-Jacobs L, Maaijwee N, Schoonderwaldt H, Dorresteijn L, van Dijk E, de Leeuw FE. 2013. Post-stroke epilepsy in young adults: A long-term follow-up study. PLoS ONE 8: e55498.

Aronica E, Boer K, van Vliet EA, Redeker S, Baayen JC, Spliet WG, van Rijen PC, Troost D, da Silva FH, Wadman WJ, et al. 2007. Complement activation in experimental and human temporal lobe epilepsy. Neurobiol Dis 26: 497511.

Aronica E, Fluiter K, Iyer A, Zurolo E, Vreijling J, van Vliet EA, Baayen JC, Gorter JA. 2010. Expression pattern of miR-146a, an inflammation-associated microRNA, in experimental and human temporal lobe epilepsy. Eur J Neurosci 31: 1100-1107.

Babb TL, Pretorius JK, Kupfer WR, Crandall PH. 1989. Glutamate decarboxylase-immunoreactive neurons are preserved in human epileptic hippocampus. J Neurosci 9: $2562-2574$

Baulac M, Pitkänen A. 2009. Research priorities in epilepsy for the next decade-A representative view of the European scientific community. Epilepsia 50: 571-583.

Bausch SB, McNamara JO. 2000. Synaptic connections from multiple subfields contribute to granule cell hyperexcitability in hippocampal slice cultures. J Neurophysiol 84: 2918-2932.

Beaumont TL, Yao B, Shah A, Kapatos G, Loeb JA. 2012. Layer-specific CREB target gene induction in human neocortical epilepsy. J Neurosci 32: 14389-14401.

Becker AJ, Chen J, Zien A, Sochivko D, Normann S, Schramm J, Elger CE, Wiestler OD, Blümcke I. 2003. Correlated stage- and subfield-associated hippocampal gene expression patterns in experimental and human temporal lobe epilepsy. Eur J Neurosci 18: 2792-2802.

Berdichevsky Y, Dzhala V, Mail M, Staley KJ. 2012. Interictal spikes, seizures and ictal cell death are not necessary for post-traumatic epileptogenesis in vitro. Neurobiol Dis 45: 774-785.

Berdichevsky Y, Dryer AM, Saponjian Y, Mahoney MM, Pimentel CA, Lucini CA, Usenovic M, Staley KJ. 2013. PI3K-Akt signaling activates mTOR-mediated epileptogenesis in organotypic hippocampal culture model of post-traumatic epilepsy. J Neurosci 33: 9056-9067.

Berg AT, Engel J Jr.. 2006. Hippocampal atrophy and the prognosis of epilepsy: Some answers, more questions. Neurology 67: 12-13.

Bertram EH, Cornett J. 1993. The ontogeny of seizures in a rat model of limbic epilepsy: Evidence for a kindling process in the development of chronic spontaneous seizures. Brain Res 625: 295-300.

Bertram EH, Cornett JF. 1994. The evolution of a rat model of chronic spontaneous limbic seizures. Brain Res 661: $157-162$.

Bolkvadze T, Pitkänen A. 2012. Development of post-traumatic epilepsy after controlled cortical impact and lateral fluid-percussion-induced brain injury in the mouse. $J$ Neurotrauma 29: 789-812.

Bot AM, Dębski KJ, Lukasiuk K. 2013. Alterations in miRNA levels in the dentate gyrus in epileptic rats. PLoS ONE 8: e76051.

Buckmaster PS. 2012. Mossy fiber sprouting in the dentate gyrus. In Jasper's basic mechanisms of the epilepsies (ed. Noebels JL, Avoli M, Rogawski MA, Olsen RW, Deelgado-Escueta AV). National Center for Biotechnology Information, Bethesda, MD.

Buckmaster PS, Dudek FE. 1997. Neuron loss, granule cell axon reorganization, and functional changes in the den- 
A. Pitkänen et al.

tate gyrus of epileptic kainate-treated rats. J Comp Neurol 385: 385-404.

Cacheaux LP, Ivens S, David Y, Lakhter AJ, Bar-Klein G, Shapira M, Heinemann U, Friedman A, Kaufer D. 2009. Transcriptome profiling reveals TGF- $\beta$ signaling involvement in epileptogenesis. J Neurosci 29: 89278935.

Casals JB, Pieri NC, Feitosa ML, Ercolin AC, Roballo KC, Barreto RS, Bressan FF, Martins DS, Miglino MA, Ambrósio CE. 2011. The use of animal models for stroke research: A review. Comp Med 61: 305-313.

Crawford F, Wood M, Ferguson S, Mathura V, Gupta P, Humphrey J, Mouzon B, Laporte V, Margenthaler E, O'Steen B, et al. 2009. Apolipoprotein E-genotype dependent hippocampal and cortical responses to traumatic brain injury. Neuroscience 159: 1349-1362.

Cronin J, Obenaus A, Houser CR, Dudek FE. 1992. Electrophysiology of dentate granule cells after kainate-induced synaptic reorganization of the mossy fibers. Brain Res 573: 305-310.

D'Ambrosio R, Miller JW. 2010. What is an epileptic seizure? Unifying definitions in clinical practice and animal research to develop novel treatments. Epilepsy Curr 10: 61-66.

D'Ambrosio R, Fairbanks JP, Fender JS, Born DE, Doyle DL, Miller JW. 2004. Post-traumatic epilepsy following fluid percussion injury in the rat. Brain 127: 304-314.

D’Ambrosio R, Fender JS, Fairbanks JP, Simon EA, Born DE, Doyle DL, Miller JW. 2005. Progression from frontal-parietal to mesial-temporal epilepsy after fluid percussion injury in the rat. Brain 128: 174-188.

D'Ambrosio R, Hakimian S, Stewart T, Verley DR, Fender JS, Eastman CL, Sheerin AH, Gupta P, Diaz-Arrastia R, Ojemann J, et al. 2009. Functional definition of seizure provides new insight into post-traumatic epileptogenesis. Brain 132: 2805-2821.

D’Ambrosio R, Eastman CL, Darvas F, Fender JS, Verley DR, Farin FM, Wilkerson HW, Temkin NR, Miller JW, Ojemann J, et al. 2013. Mild passive focal cooling prevents epileptic seizures after head injury in rats. Ann Neurol 73: 199-209.

Darrah SD, Miller MA, Ren D, Hoh NZ, Scanlon JM, Conley YP, Wagner AK. 2013. Genetic variability in glutamic acid decarboxylase genes: Associations with post-traumatic seizures after severe TBI. Epilepsy Res 103: 180-194.

Diamond ML, Ritter AC, Failla MD, Boles JA, Conley YP, Kochanek PM, Wagner AK. 2014. IL-1 $\beta$ associations with posttraumatic epilepsy development: A genetics and biomarker cohort study. Epilepsia 55: 1109-1119.

Dudek FE, Bertram EH. 2010. Counterpoint to "What is an epileptic seizure"? by D’Ambrosio and Miller. Epilepsy Curr 10: 91-94.

Dudek FE, Staley KJ. 2011. The time course of acquired epilepsy: Implications for therapeutic intervention to suppress epileptogenesis. Neurosci Lett 497: 240-246.

Dudek FE, Staley KJ. 2012. The time course and circuit mechanisms of acquired epileptogenesis. In Jasper's basic mechanisms of the epilepsies (ed. Noebels JL, et al.). National Center for Biotechnology Information, Bethesda, MD.
Dyhrfjeld-Johnsen J, Berdichevsky Y, Swiercz W, Sabolek H, Staley KJ. 2010. Interictal spikes precede ictal discharges in an organotypic hippocampal slice culture model of epileptogenesis. J Clin Neurophysiol 27: 418-424.

Elliott RC, Miles MF, Lowenstein DH. 2003. Overlapping microarray profiles of dentate gyrus gene expression during development- and epilepsy-associated neurogenesis and axon outgrowth. J Neurosci 23: 2218-2227.

Engel J Jr. 1996. Clinical evidence for the progressive nature of epilepsy. Epilepsy Res Suppl 12: 9-20.

Engel J Jr. 2005. Epilepsy and seizure disorder. Epilepsia 46: 1333.

Engel J Jr. 2008. Progress in epilepsy: Reducing the treatment gap and the promise of biomarkers. Curr Opin Neurol 21: $150-154$.

Engel J Jr, Pitkänen A, Loeb JA, Dudek FE, Bertram EH III, Cole AJ, Moshé SL, Wiebe S, Jensen FE, Mody I, et al. 2013. Epilepsy biomarkers. Epilepsia 54 (Suppl 4): 6169.

Filibian M, Frasca A, Maggioni D, Micotti E, Vezzani A, Ravizza T. 2012. In vivo imaging of glia activation using $1 \mathrm{H}$-magnetic resonance spectroscopy to detect putative biomarkers of tissue epileptogenicity. Epilepsia 53: 19071916.

Giger RJ, Hollis ER, Tuszynski MH. 2010. Guidance molecules in axon regeneration. Cold Spring Harb Perspect Biol 2: a001867.

Goffin K, Nissinen J, Van LK, Pitkänen A. 2007. Cyclicity of spontaneous recurrent seizures in pilocarpine model of temporal lobe epilepsy in rat. Exp Neurol 205: 501-505.

Gorter JA, van Vliet EA, Aronica E, Lopes da Silva FH. 2001. Progression of spontaneous seizures after status epilepticus is associated with mossy fibre sprouting and extensive bilateral loss of hilar parvalbumin and somatostatin-immunoreactive neurons. Eur J Neurosci 13: 657-669.

Gorter JA, van Vliet EA, Aronica E, Breit T, Rauwerda H, Lopes da Silva FH, Wadman WJ. 2006. Potential new antiepileptogenic targets indicated by microarray analysis in a rat model for temporal lobe epilepsy. J Neurosci 26: $11083-11110$

Gorter JA, Van Vliet EA, Rauwerda H, Breit T, Stad R, van Schaik L, Vreugdenhil E, Redeker S, Hendriksen E, Aronica E, et al. 2007. Dynamic changes of proteases and protease inhibitors revealed by microarray analysis in CA3 and entorhinal cortex during epileptogenesis in the rat. Epilepsia 48 : 53-64.

Gorter JA, Iyer A, White I, Colzi A, van Vliet EA, Sisodiya S, Aronica E. 2014. Hippocampal subregion-specific microRNA expression during epileptogenesis in experimental temporal lobe epilepsy. Neurobiol Dis 62: 508-520.

Graham NS, Crichton S, Koutroumanidis M, Wolfe CD, Rudd AG. 2013. Incidence and associations of poststroke epilepsy: The prospective South London stroke register. Stroke 44: 605-611.

Guo D, Zeng L, Brody DL, Wong M. 2013. Rapamycin attenuates the development of posttraumatic epilepsy in a mouse model of traumatic brain injury. PLoS ONE 8: e64078.

Heinemann U, Staley KJ. 2014. What is the clinical relevance of in vitro epileptiform activity? Adv Exp Med Biol 813: $25-41$. 
Hellier JL, Patrylo PR, Buckmaster PS, Dudek FE. 1998 Recurrent spontaneous motor seizures after repeated low-dose systemic treatment with kainate: Assessment of a rat model of temporal lobe epilepsy. Epilepsy Res 31: 73-84

Hendriksen H, Datson NA, Ghijsen WE, van Vliet EA, da Silva FH, Gorter JA, Vreugdenhil E. 2001. Altered hippocampal gene expression prior to the onset of spontaneous seizures in the rat post-status epilepticus model. Eur J Neurosci 14: 1475-1484.

Henshall JM, Dierens L, Sellars MJ. 2014. Quantitative analysis of low-density SNP data for parentage assignment and estimation of family contributions to pooled samples. Genet Sel Evol 46: 51.

Hesdorffer DC, Logroscino G, Cascino G, Annegers JF, Hauser WA. 1998. Risk of unprovoked seizure after acute symptomatic seizure: Effect of status epilepticus. Ann Neurol 44: 908-912.

Holtman L, van Vliet EA, Aronica E, Wouters D, Wadman WJ, Gorter JA. 2013. Blood plasma inflammation markers during epileptogenesis in post-status epilepticus rat model for temporal lobe epilepsy. Epilepsia 54: 589-595.

Hu XL, Cheng X, Cai L, Tan GH, Xu L, Feng XY, Lu TJ, Xiong H, Fei J, Xiong ZQ. 2011. Conditional deletion of NRSF in forebrain neurons accelerates epileptogenesis in the kindling model. Cereb Cortex 21: 2158-2165.

Hu Z, Yu D, Almeida-Suhett C, Tu K, Marini AM, Eiden L, Braga MF, Zhu J, Li Z. 2012. Expression of miRNAs and their cooperative regulation of the pathophysiology in traumatic brain injury. PLoS ONE 7: e39357.

Hunt RF, Scheff SW, Smith BN. 2009. Posttraumatic epilepsy after controlled cortical impact injury in mice. Exp Neurol 215: $243-252$.

Hunt RF, Scheff SW, Smith BN. 2010. Regionally localized recurrent excitation in the dentate gyrus of a cortical contusion model of posttraumatic epilepsy. J Neurophysiol 103: $1490-1500$.

Ioannidis JP, Allison DB, Ball CA, Coulibaly I, Cui X, Culhane AC, Falchi M, Furlanello C, Game L, Jurman G, et al. 2009. Repeatability of published microarray gene expression analyses. Nat Genet 41: 149-155.

Iyer A, Zurolo E, Prabowo A, Fluiter K, Spliet WG, van Rijen PC, Gorter JA, Aronica E. 2012. MicroRNA-146a: A key regulator of astrocyte-mediated inflammatory response. PLOS ONE 7: e44789.

Jennett B, Van De Sande J. 1975. EEG prediction of posttraumatic epilepsy. Epilepsia 16: 251-256.

Jirsa VK, Stacey WC, Quilichini PP, Ivanov AI, Bernard C. 2014. On the nature of seizure dynamics. Brain 137: 2210-2230.

Jovičić A, Roshan R, Moisoi N, Pradervand S, Moser R, Pillai B, Luthi-Carter R. 2013. Comprehensive expression analyses of neural cell-type-specific miRNAs identify new determinants of the specification and maintenance of neuronal phenotypes. J Neurosci 33: 5127-5137.

Kadam SD, White AM, Staley KJ, Dudek FE. 2010. Continuous electroencephalographic monitoring with radio-telemetry in a rat model of perinatal hypoxia-ischemia reveals progressive post-stroke epilepsy. J Neurosci 30: 404-415.
Kandel ER, Markram H, Matthews PM, Yuste R, Koch C. 2013. Neuroscience thinks big (and collaboratively). Nat Rev Neurosci 14: 659-664.

Kanner AM, Mazarati A, Koepp M. 2014. Biomarkers of epileptogenesis: Psychiatric comorbidities (?). Neurotherapeutics 11: 358-372.

Karhunen H, Pitkänen A, Virtanen T, Gureviciene I, Pussinen R, Ylinen A, Sivenius J, Nissinen J, Jolkkonen J. 2003 Long-term functional consequences of transient occlusion of the middle cerebral artery in rats: A 1-year followup of the development of epileptogenesis and memory impairment in relation to sensorimotor deficits. Epilepsy Res 54: $1-10$.

Karhunen H, Nissinen J, Sivenius J, Jolkkonen J, Pitkänen A. 2006. A long-term video-EEG and behavioral follow-up after endothelin-1 induced middle cerebral artery occlusion in rats. Epilepsy Res 72: 25-38.

Karhunen H, Bezvenyuk Z, Nissinen J, Sivenius J, Jolkkonen J, Pitkänen A. 2007. Epileptogenesis after cortical photothrombotic brain lesion in rats. Neuroscience 148: 314324.

Kelley MS, Jacobs MP, Lowenstein DH; NINDS Epilepsy Benchmark Stewards. 2009. The NINDS epilepsy research benchmarks. Epilepsia 50: 579-582.

Kelly KM. 2004. Spike-wave discharges: Absence or not, a common finding in common laboratory rats. Epilepsy Curr 4: 176-177.

Kelly KM, Kharlamov A, Hentosz TM, Kharlamova EA, Williamson JM, Bertram EH III, Kapur J, Armstrong DM. 2001. Photothrombotic brain infarction results in seizure activity in aging Fischer 344 and Sprague Dawley rats. Epilepsy Res 47: 189-203.

Kelly KM, Jukkola PI, Kharlamov EA, Downey KL, McBride JW, Strong R, Aronowski J. 2006. Long-term video-EEG recordings following transient unilateral middle cerebral and common carotid artery occlusion in Long-Evans rats. Exp Neurol 201: 495-506.

Kharatishvili I, Nissinen JP, McIntosh TK, Pitkänen A. 2006. A model of posttraumatic epilepsy induced by lateral fluid-percussion brain injury in rats. Neuroscience 140: 685-697.

Kharatishvili I, Immonen R, Gröhn O, Pitkänen A. 2007. Quantitative diffusion MRI of hippocampus as a surrogate marker for post-traumatic epileptogenesis. Brain 130: $3155-3168$

Kharlamov EA, Jukkola PI, Schmitt KL, Kelly KM. 2003. Electrobehavioral characteristics of epileptic rats following photothrombotic brain infarction. Epilepsy Res 56: $185-203$.

Kobori N, Clifton GL, Dash P. 2002. Altered expression of novel genes in the cerebral cortex following experimental brain injury. Brain Res Mol Brain Res 104: 148-158.

Kobow K, Blümcke I. 2014. Epigenetic mechanisms in epilepsy. Prog Brain Res 213: 279-316.

Kobow K, Kaspi A, Harikrishnan KN, Kiese K, Ziemann M, Khurana I, Fritzsche I, Hauke J, Hahnen E, Coras R, et al. 2013. Deep sequencing reveals increased DNA methylation in chronic rat epilepsy. Acta Neuropathol 126: 741756.

Kojima N, Borlikova G, Sakamoto T, Yamada K, Ikeda T, Itohara S, Niki H, Endo S. 2008. Inducible cAMP early 
repressor acts as a negative regulator for kindling epileptogenesis and long-term fear memory. J Neurosci 28: 6459-6472.

Laurén HB, Lopez-Picon FR, Brandt AM, Rios-Rojas CJ, Holopainen IE. 2010. Transcriptome analysis of the hippocampal CA1 pyramidal cell region after kainic acidinduced status epilepticus in juvenile rats. PLOS ONE 5: e10733.

Lew FH, Buckmaster PS. 2011. Is there a critical period for mossy fiber sprouting in a mouse model of temporal lobe epilepsy? Epilepsia 52: 2326-2332.

Li A, Choi YS, Dziema H, Cao R, Cho HY, Jung YJ, Obrietan K. 2010. Proteomic profiling of the epileptic dentate gyrus. Brain Pathol 20: 1077-1089.

Liu J, Schmitt KL, Kharlamov EA, Stolarski CJ, Grayson DR, Kelly KM. 2002. Quantitative reverse transcription-polymerase chain reaction of $\mathrm{GABA}_{\mathrm{A}} \alpha_{1}, \beta_{1}$ and $\gamma_{2 \mathrm{~S}}$ subunits in epileptic rats following photothrombotic infarction of neocortex. Epilepsy Res 52: 85-95.

Liu DZ, Tian Y, Ander BP, Xu H, Stamova BS, Zhan X, Turner RJ, Jickling G, Sharp FR. 2010. Brain and blood microRNA expression profiling of ischemic stroke, intracerebral hemorrhage, and kainate seizures. J Cereb Blood Flow Metab 30: 92-101.

Lukasiuk K, Becker AJ. 2014. Molecular biomarkers of epileptogenesis. Neurotherapeutics 11: 319-323.

Lukasiuk K, Kontula L, Pitkänen A. 2003. cDNA profiling of epileptogenesis in the rat brain. Eur J Neurosci 17: 271279.

Lukasiuk K, Dabrowski M, Adach A, Pitkänen A. 2006. Epileptogenesis-related genes revisited. Prog Brain Res 158 223-241.

MacVicar BA, Dudek FE. 1980. Local synaptic circuits in rat hippocampus: Interactions between pyramidal cells. Brain Res 184: 220-223.

Mátéffyová A, Otáhal J, Tsenov G, Mares P, Kubová H. 2006. Intrahippocampal injection of endothelin-1 in immature rats results in neuronal death, development of epilepsy and behavioral abnormalities later in life. Eur J Neurosci 24: $351-360$.

McBain CJ, Boden P, Hill RG. 1989. Rat hippocampal slices "in vitro" display spontaneous epileptiform activity following long-term organotypic culture. J Neurosci Methods 27: 35-49.

McClelland S, Brennan GP, Dubé C, Rajpara S, Iyer S, Richichi C, Bernard C, Baram TZ. 2014. The transcription factor NRSF contributes to epileptogenesis by selective repression of a subset of target genes. eLife 3: e01267.

Miles R, Wong RK. 1987. Inhibitory control of local excitatory circuits in the guinea-pig hippocampus. J Physiol 388: $611-629$.

Miller MA, Conley Y, Scanlon JM, Ren D, Ilyas Kamboh M, Niyonkuru C, Wagner AK. 2010. APOE genetic associations with seizure development after severe traumatic brain injury. Brain Inj 24: 1468-1477.

Ndode-Ekane XE, Pitkänen A. 2013. Urokinase-type plasminogen activator receptor modulates epileptogenesis in mouse model of temporal lobe epilepsy. Mol Neurobiol 47: 914-937.

Nissinen J, Halonen T, Koivisto E, Pitkänen A. 2000. A new model of chronic temporal lobe epilepsy induced by elec- trical stimulation of the amygdala in rat. Epilepsy Res 38: $177-205$.

Okamoto OK, Janjoppi L, Bonone FM, Pansani AP, da Silva AV, Scorza FA, Cavalheiro EA. 2010. Whole transcriptome analysis of the hippocampus: toward a molecular portrait of epileptogenesis. BMC Genomics 11: 230.

Pearce PS, Friedman D, Lafrancois JJ, Iyengar SS, Fenton AA, Maclusky NJ, Scharfman HE. 2014. Spike-wave discharges in adult Sprague-Dawley rats and their implications for animal models of temporal lobe epilepsy. Epilepsy Behav 32: 121-131.

Perin R, Berger TK, Markram H. 2011. A synaptic organizing principle for cortical neuronal groups. Proc Natl Acad Sci 108: 5419-5424.

Pitkänen A, Engel J Jr. 2014. Past and present definitions of epileptogenesis and its biomarkers. Neurotherapeutics 11: $231-241$.

Pitkänen A, Immonen R. 2014. Epilepsy related to traumatic brain injury. Neurotherapeutics 11: 286-296.

Pitkänen A, Kubova H. 2004. Antiepileptic drugs in neuroprotection. Expert Opin Pharmacother 5: 777-798.

Pitkänen A, Lukasiuk K. 2011. Mechanisms of epileptogenesis and potential treatment targets. Lancet Neurol 10: 173-186.

Pitkänen A, Nissinen J, Nairismagi J, Lukasiuk K, Gröhn OHJ Miettinen R, Kauppinen R. 2002. Progression of neuronal damage after status epilepticus and during spontaneous seizures in a rat model of temporal lobe epilepsy. Prog Brain Res 135: 67-83.

Pitkänen A, Nehlig A, Brooks-Kayal AR, Dudek FE, Friedman D, Galanopoulou AS, Jensen FE, Kaminski RM, Kapur J, Klitgaard H, et al. 2013. Issues related to development of antiepileptogenic therapies. Epilepsia 54: 35-43.

Pitkänen A, Huusko N, Ndode-Ekane XE, Kyyriäinen J, Lipponen A, Lipsanen A, Sierra A, Bolkvadze T. 2014. Gender issues in antiepileptogenic treatments. Neurobiol Dis 72PB: 224-232.

Porter BE, Lund IV, Varodayan FP, Wallace RW, Blendy JA. 2008. The role of transcription factors cyclic-AMP responsive element modulator (CREM) and inducible cyclic-AMP early repressor (ICER) in epileptogenesis. Neuroscience 152: 829-836.

Rakhade SN, Jensen FE. 2009. Epileptogenesis in the immature brain: Emerging mechanisms. Nat Rev Neurol 5: 380-391.

Risbud RM, Porter BE. 2013. Changes in microRNA expression in the whole hippocampus and hippocampal synaptoneurosome fraction following pilocarpine induced status epilepticus. PLoS ONE 8: e53464.

Saatman KE, Duhaime AC, Bullock R, Maas AI, Valadka A, Manley GT. 2008. Classification of traumatic brain injury for targeted therapies. J Neurotrauma 25: 719-738.

Schauwecker PE, Ramirez JJ, Steward O. 2000. Genetic dissection of the signals that induce synaptic reorganization. Exp Neurol 161: 139-152.

Shao LR, Dudek FE. 2005. Changes in mIPSCs and sIPSCs after kainate treatment: Evidence for loss of inhibitory input to dentate granule cells and possible compensatory responses. J Neurophysiol 94: 952-960. 
Shultz SR, Cardamone L, Liu YR, Hogan RE, Maccotta L, Wright DK, Zheng P, Koe A, Gregoire MC, Williams JP, et al. 2013. Can structural or functional changes following traumatic brain injury in the rat predict epileptic outcome? Epilepsia 54: 1240-1250.

Simonato M, Loscher W, Cole AJ, Dudek FE, Engel J, Kaminski RM, Loeb JA, Scharfman H, Staley KJ, Velisek L, et al. 2012. Finding a better drug for epilepsy: Preclinical screening strategies and experimental trial design. Epilepsia 53: 1860-1867.

Sloviter RS. 1991. Permanently altered hippocampal structure, excitability, and inhibition after experimental status epilepticus in the rat: The "dormant basket cell" hypothesis and its possible relevance to temporal lobe epilepsy. Hippocampus 1: 41-66.

Statler KD, Scheerlinck P, Pouliot W, Hamilton M, White HS, Dudek FE. 2009. A potential model of pediatric posttraumatic epilepsy. Epilepsy Res 86: 221-223.

Sutula TP, Dudek FE. 2007. Unmasking recurrent excitation generated by mossy fiber sprouting in the epileptic dentate gyrus: An emergent property of a complex system. Prog Brain Res 163: 541-563.

Tauck DL, Nadler JV. 1985. Evidence of functional mossy fiber sprouting in hippocampal formation of kainic acidtreated rats. J Neurosci 5: 1016-1022.

Theilhaber J, Rakhade SN, Sudhalter J, Kothari N, Klein P, Pollard J, Jensen FE. 2013. Gene expression profiling of a hypoxic seizure model of epilepsy suggests a role for mTOR and Wnt signaling in epileptogenesis. PLoS ONE 8: e74428.
Thind KK, Yamawaki R, Phanwar I, Zhang G, Wen X, Buckmaster PS. 2010. Initial loss but later excess of GABAergic synapses with dentate granule cells in a rat model of temporal lobe epilepsy. J Comp Neurol 518: 647-667.

Wagner AK, Miller MA, Scanlon J, Ren D, Kochanek PM, Conley YP. 2010. Adenosine Al receptor gene variants associated with post-traumatic seizures after severe TBI. Epilepsy Res 90: 259-272.

White A, Williams PA, Hellier JL, Clark S, Dudek FE, Staley KJ. 2010. EEG spike activity precedes epilepsy after kainate-induced status epilepticus. Epilepsia 51: 371-383.

Williams PA, White AM, Clark S, Ferraro DJ, Swiercz W, Staley KJ, Dudek FE. 2009. Development of spontaneous recurrent seizures after kainate-induced status epilepticus. J Neurosci 29: 2103-2112.

Winden KD, Karsten SL, Bragin A, Kudo LC, Gehman L, Ruidera J, Geschwind DH, Engel J Jr. 2011. A systems level, functional genomics analysis of chronic epilepsy. PLOS ONE 6: e20763.

Xiong Y, Mahmood A, Chopp M. 2013. Animal models of traumatic brain injury. Nat Rev Neurosci 14: 128-142.

Zhang W, Yamawaki R, Wen X, Uhl J, Diaz J, Prince DA, Buckmaster PS. 2009. Surviving hilar somatostatin interneurons enlarge, sprout axons, and form new synapses with granule cells in a mouse model of temporal lobe epilepsy. J Neurosci 29: 14247-14256.

Zhang Y, Liao Y, Wang D, He Y, Cao D, Zhang F, Dou K. 2011 Altered expression levels of miRNAs in serum as sensitive biomarkers for early diagnosis of traumatic injury. J Cell Biochem 112: 2435-2442. 


\section{$\& \mathrm{CSH} \&$ Cold Spring Harbor

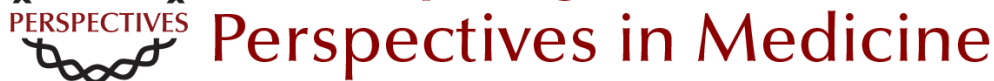

\section{Epileptogenesis}

Asla Pitkänen, Katarzyna Lukasiuk, F. Edward Dudek and Kevin J. Staley

Cold Spring Harb Perspect Med 2015; doi: 10.1101/cshperspect.a022822 originally published online September 18, 2015

\section{Subject Collection Epilepsy: The Biology of a Spectrum Disorder}

The Epilepsy Spectrum: Targeting Future Research Challenges

Gregory L. Holmes and Jeffrey L. Noebels

Role of Sodium Channels in Epilepsy

David I. Kaplan, Lori L. Isom and Steven Petrou

\section{Mechanisms of Action of Antiseizure Drugs and the Ketogenic Diet \\ Michael A. Rogawski, Wolfgang Löscher and Jong M. Rho}

Epilepsy and Autism

Ashura W. Buckley and Gregory L. Holmes

Immunity and Inflammation in Epilepsy

Annamaria Vezzani, Bethan Lang and Eleonora Aronica

Hyperpolarization-Activated Cyclic

Nucleotide-Gated (HCN) Channels in Epilepsy Gary P. Brennan, Tallie Z. Baram and Nicholas P. Poolos

The Role of Calcium Channels in Epilepsy Sanjeev Rajakulendran and Michael G. Hanna

Interneuron Transplantation as a Treatment for Epilepsy

Robert F. Hunt and Scott C. Baraban
Common Mechanisms Underlying

Epileptogenesis and the Comorbidities of

Epilepsy

Andrey Mazarati and Raman Sankar

The Diathesis-Epilepsy Model: How Past Events Impact the Development of Epilepsy and

Comorbidities

Christophe Bernard

Potassium Channels in Epilepsy

Rüdiger Köhling and Jakob Wolfart

GABAergic Synchronization in Epilepsy Roustem Khazipov

Status Epilepticus

Syndi Seinfeld, Howard P. Goodkin and Shlomo Shinnar

Neonatal and Infantile Epilepsy: Acquired and

Genetic Models Aristea S. Galanopoulou and Solomon L. Moshé

Epigenetics and Epilepsy

David C. Henshall and Katja Kobow

Microcircuits in Epilepsy: Heterogeneity and Hub Cells in Network Synchronization

Anh Bui, Hannah K. Kim, Mattia Maroso, et al.

For additional articles in this collection, see http://perspectivesinmedicine.cshlp.org/cgi/collection/ 